\title{
humanidades
}

Revista humanidades

Diciembre, 2014 •Volumen 4 • ISSN 2215-3934 • pp. 1-31

\section{Fenomenología de la fe y antropología en Edith Stein: En miras de una pedagogía empática}

DOI: http://dx.doi.org/10.15517/h.v4i1.16321

Recibido: 29-Mayo-2014 / Aceptado: 07-Julio-2014

\section{Pablo Céspedes Solís}

Máster, consultor independiente.

Correo electrónico: pacesescazu@ gmail.com 


\section{Fenomenología de la fe y antropología en Edith Stein: En miras de una pedagogía empática}

\section{Resumen}

El presente trabajo aborda los contextos históricos y filosóficos de principios de siglo XX en Europa, particularmente Alemania, para comprender la vida, obra y pensamiento de Edith Stein (santa Teresa Benedicta de la Cruz). Se hará un análisis Palabras clave: Edith Stein, fenomenología, filosofía alemana, pedagogía, antropología filosófica. primordial de su obra en torno a la antropología filosófica, la fenomenología de la fe y la pedagogía. Se pretende hacer una reflexión que busque los posibles aportes de esta pensadora a las ciencias sociales y las letras latinoamericanas.

\section{Phenomenology of faith and anthropology in Edith Stein: In view of an empathic pedagogy}

\section{Abstract}

This paper addresses the philosophical and historical contexts of early twentieth-century Europe, particularly Germany, in order to better understand the life, work and thought of Edith Stein (Saint Teresa Benedicta of the Cross). A primary analysis of Stein's work in philosophical anthropology and the phenomenology of faith and pedagogy will be presented, followed by a reflection on her possible contribution to Latin American social science and literature.
Keywords: Edith Stein, phenomenology, German philosophy, pedagogy, philosophical anthropology. 
Edith Stein, filósofa, teóloga y mártir alemana del siglo XX, ha sido declarada santa por la Iglesia católica, como copatrona de Europa. Una vida cargada de intensidad y que siempre estuvo movida por una pasión: buscar la verdad. Esta búsqueda de la verdad la llevó a dialogar con las corrientes filosóficas, políticas y teológicas de su entorno. Forjó un pensamiento caracterizado por un elevado sentido de justicia y racionalidad, lo que la llevó a tomar posiciones leales y firmes. Fue una mujer coherente entre lo que pensaba y vivía, tanto así que su misma convicción la llevaría, incluso, a su propia muerte.

Stein es una figura poco conocida en Latinoamérica; sin embargo, como protagonista de primer orden del siglo pasado, su testimonio y pensamiento traspasan los límites espaciales y temporales, por lo que siempre tendrá mucho que decirnos en América Latina, hoy.

El presente artículo se divide en cinco secciones. La primera analiza la posición alemana dentro de la I Guerra Mundial, además, la raíces antisemíticas que brotaron del nacionalismo alemán, principios que llevarían al exterminio de judíos alemanes. La segunda sección aborda la filosofía alemana de primera mitad de siglo XX, se enfatiza en el aporte de la fenomenología, escuela a la que se adhirió Edith en sus primeros años. Una tercera parte aborda la propuesta steiniana de la antropología filosófica; desde allí, se podrán comprender los conceptos fundamentales de su propuesta 
pedagógica. En un cuarto momento, se retomará la propuesta fenomenológica de la fe de esta pensadora. Por último, se hará una reflexión sobre los posibles aportes de la obra de Stein para las ciencias sociales latinoamericanas.

Edith Stein, de origen judío, nació el 12 de octubre de 1891 en Breslau, Reseña Alemania. Siendo una adolescente de 14 años abandona los estudios y la fe. biográfica Superada la crisis, con 20 años de edad, obtuvo brillantemente la reválida e inicia los estudios superiores en la Universidad de Breslau, matriculándose en germanística, historia y psicología. Posteriormente, entra en conflicto con la psicología y empieza a leer Investigaciones lógicas de Edmund Husserl. Ese mismo año abandona la universidad, para iniciar nuevos estudios con el deseo de conocer profundamente el misterio del ser humano.

En 1913, atraída por la fenomenología de Husserl, ingresa a la Universidad de Gotinga donde continúa sus estudios. Ante el estallido de la I Guerra Mundial, se alista voluntariamente como asistente de enfermera de la Cruz Roja. En 1916 defiende su tesis doctoral Sobre el problema de la Empatía, teniendo como director a Husserl. No consigue habilitación como docente por su condición de mujer judía.

Una mañana de 1920, en las afueras de la antigua Catedral de Frankfurt, la Doctora Edith Stein se encontró con el profesor Paul Reinach; entraron unos minutos a la Catedral y mientras estaban allí, en respetuoso silencio, "entró una señora con su cesto del mercado, y se arrodilló en un banco, para hacer una 
breve oración" comenta Edith en su autobiografía. Este simple hecho marcó la conciencia y personalidad de la filósofa atea. Continúa escribiendo: "Esto fue para mí algo totalmente nuevo. En las sinagogas y en las iglesias protestantes, a las que había ido, se iba solamente para los oficios religiosos. Pero aquí llega cualquiera en medio de los trabajos diarios a la iglesia vacía como para un diálogo confidencial. Esto no lo he podido olvidar" (Cfr. Sullivan, 2003, p. 117). Desde este momento, la filósofa agnóstica, paladín del novísimo método fenomenológico, iniciará una nueva búsqueda de la verdad.

Un día del mes de junio de aquel mismo año, mientras visitaba a su amiga, la filósofa Hedwig Conrad-Martius, lee la autobiografía de santa Teresa de Jesús. Solo una madrugada le bastó. Al terminar la lectura, decide convertirse al catolicismo. Se aventura a dar el paso gigantesco de la fe. "Esta es la verdad", dijo al cerrar el libro (Gil de Muro, 1998, p. 129).

Un 1 de enero del 1922 es bautizada y una vez vinculada al mundo católico, da clases de literatura y alemán en el Seminario de pedagogía e Instituto de las Dominicas de Santa Magdalena de Espira. Imparte clases sobre la cuestión femenina y la educación católica en países germano-parlantes y comienza a confrontar los datos de la fe con la filosofía fenomenológica. Además, inicia la traducción de la obra de Santo Tomás de Aquino De Veritate. Para el 70 aniversario del natalicio de su maestro, le dedica la obra La fenomenología de Husserl y la filosofía de Santo Tomás. 
El 15 de octubre de 1933, ingresa al Carmelo de Colonia. Ante la barbarie antisemita de la política hitleriana, en abril de 1942 fue registrada, junto con su hermana Rosa, por la Gestapo. Fue enviada a Holanda para salvaguardar su vida; sin embargo, el 2 de agosto la policía alemana invade el Convento de Echt (Holanda) y encarcelan a Edith y a Rosa por su origen judío. Ella y su hermana son asesinadas en las cámaras de gas el 9 de agosto de 1942 en Auschwitz.

El papa Juan Pablo II durante la homilía de su beatificación dijo:

Edith Stein, Teresa Benedicta de la Cruz: Una personalidad que reúne en su rica vida una síntesis dramática de nuestro siglo. La síntesis de una historia llena de heridas profundas, que siguen doliendo todavía hoy, pero que hombres y mujeres con sentido de responsabilidad se han esforzado y siguen esforzando por curar; síntesis, al mismo tiempo, de la verdad plena sobre el hombre, en un corazón que estuvo inquieto e insatisfecho 'hasta que encontró su descanso en Dios' (Juan Pablo II, Homilía de Beatificación: Colonia, 1 de mayo de 1987).

A mediados del XIX, Prusia se hizo del control político y económico de la Confederación alemana. Guillermo I y su jefe de gobierno, Otto von Bismark, hicieron reformas importantes. A la muerte de Guillermo I, le sucede Guillermo II, destituye a Bismark y empieza una nueva diplomacia europea. Para este momento la carrera armamentista de Europa avanzaba temiblemente.

El Imperio Alemán, el pangermanismo y la Gran Guerra 
La II Revolución Industrial trajo consigo una oferta bélica impresionante. El mismo ferrocarril serviría de aliado, en caso de guerra, para el desplazamiento a grandes distancias. Todos los países europeos preparaban soldados, poseían grandes reservas de armas y ejércitos competentes. Durante la paz armada, Francia y Alemania podían movilizar en pocos días a un millón de hombres. Conforme se acercaba una situación bélica, crecía el patriotismo agresivo, síntomas nefastos del más brutal nacionalismo. Situación gravemente marcada en Alemania donde circulaba información pangermánica y antisemita. Más de dos décadas de tensión terminarían con la guerra.

En 1914, Alemania era una potencia industrial, militar, naval y comercial. Su posición estratégica, en el centro de Europa, le creaba ventajas y desventajas en un eventual enfrentamiento. En ese mismo año, un nacionalista serbio asesina al heredero del trono Austro-Húngaro, el Archiduque Francisco Fernando en Sarajevo. En julio, Austria y Alemania le declaran la guerra a Serbia. Por las Alianzas pactadas y el sistema de "padrinazgos" entre las potencias, el conflicto se expandió a casi todo el continente. Prácticamente eran Francia, Rusia, Inglaterra y Japón contra Alemania-Austria.

Tardíamente, el Imperio Otomano y las fuerzas italianas apoyarían las potencias centrales. Una guerra con Alemania como eje y con dos frentes: al oeste enfrentaba a Francia y Gran Bretaña; y al este enfrentaba a Rusia. Se trata de la primera guerra moderna de la historia. Tecnologías novedosas y 
mortíferas, guerra aérea, alianzas y pactos de protección, millones de muertos, decenas de países que intervinieron y el papel de las mujeres en la guerra. Cosa insólita antes de la I Guerra Mundial.

Miles de mujeres prestaron servicios voluntarios como enfermeras y conductoras de ambulancias. Edith ingresó como enfermera voluntaria a un hospital austríaco. La guerra avanzaba, parecía interminable. En lugar de achicarse, se expandía hacia otras latitudes. Alemania enfrentó, al oeste, a Francia y Gran Bretaña, pero obtuvo desastrosos resultados.

Empieza la retirada de los alemanes. La situación se fue complicando cada vez más, hasta que el 11 de noviembre de 1918 los alemanes firmaron un armisticio. Una guerra en la que todos creían terminaría pronto, tardó cuatro años dolorosos. Millones de muertos y el rostro de Europa cambiado para siempre. Alemania es la gran protagonista de esta guerra.

La situación alemana era complicada. Termina una guerra en la que resulta una nación perdedora. Los vencedores se reparten las colonias alemanas y delinean los nuevos límites fronterizos. El pueblo se siente terriblemente dolido y desconcertado. Empiezan las pequeñas revoluciones internas y los conflictos sociales. Alemania pide paz sobre la base de los "14 puntos", propuestos por Woodrow Wilson. 
El emperador Guillermo II renuncia a su cargo político, con lo cual se abre la posibilidad de instaurar la República de Weimar. "Los escritos de Edith Stein en estos momentos son reflejo claro de su preocupación por dar una solución con fundamentos claros a la situación" (Sancho, 1998, p. 675).

En Alemania, donde el sentimiento de derrota está anclado en el corazón de su pueblo, el partido Nazi, dirigido por Adolfo Hitler, pretende revivir la gloria que una vez tuvo el imperio. El derrotismo psicológico del pueblo, las ansias locas de un demagogo y los deseos de devolverle a Alemania su antiguo esplendor, llevarían a Alemania (y a toda Europa) a otra guerra. Con todo, ya en el alba de su conversión, crecía en Alemania la oleada del odio nazista que arrasaría al pueblo hebreo mediante el exterminio e incendiaría a toda Europa con la II Guerra Mundial.

Edith Stein observa con impresionante lucidez la evolución del drama sociopolítico y con su despierto olfato para el análisis político había visto venir la desgracia ya mucho antes. Una colega de Espira llega incluso a afirmar que Edith Stein había dicho ya en 1918, cuando los ocupantes franceses se marcharon y las tropas alemanas fueron recibidas con júbilo: "Ya verán; ahora comienza una persecución de judíos y posteriormente de la Iglesia" (Feldmann, 1999, p. 86).

El Tratado de Versalles (1919) no logró ordenar y pacificar las naciones europeas. La tensión y el conflicto siempre estaban latentes. El nuevo orden 
mundial estaba controlado, cada vez más, por los Estados Unidos de Norteamérica. Europa estaba en crisis: recesiones económicas, hambrunas, gobiernos dictatoriales, nacionalismos agresivos, etc. En Alemania, Hitler funda el partido Nazi y en 1933 llega a la cancillería, donde asume poderes plenipotenciales. Empieza, entonces, el rearme alemán con vistas a no perder una guerra más, fundar el Tercer Reich y colocar a Alemania su punto central de la historia.

El Reichtag concede todos los poderes al Führer y comienza un sistema totalitario de gobierno. El Führer desintegra todos los demás partidos, depura ideológicamente la justicia y organiza nuevamente la Gestapo (policía estatal). La fuerza ideológica tenía tres objetivos: antisemitismo, antimarxismo y nacionalismo expansionista. Los escritos de W. Marr en Alemania y la aparición de doctrinas pseudocientíficas sobre la superioridad del hombre ario (Rosenberg) provocaron un nuevo antisemitismo en la era hitleriana.

La revista panfletaria Stürmer titulaba siempre "Los judíos nuestra desgracia", revista terriblemente sanguinaria y exitosa. Su editor Julios Streicher «había dado a conocer ya en 1926 la sorprendente teoría de la "albúmina de otra especie" con al que la "perruna raza judía" pretendía envenenar la sangre de las mujeres arias» (Feldmann, 1999, p. 86). Para esta época, Edith viajaba en varias ciudades de Alemania y Austria, dictaba conferencias sobre formación cristiana. 
Para los nazis ella representaba una "amenaza" al sistema. Como lo afirma Ciro García: "La persecución de los no-arios bajo el nacionalsocialismo fue tomando perfiles cada vez más dramáticos" (1998, p. 169). Ante esta nueva situación, Edith estaba triplemente amenazada: por ser paladín de la conciencia política durante sus conferencias, por promover una recuperación del sentido espiritual del ser humano y por ser judía conversa, por lo tanto, no aria.

La tragedia se asoma. Hitler firma con Mussolini la asistencia mutua (Eje Roma-Berlín, 1936). El Führer toma Austria y zonas de la República Checa. La diplomacia trabajaba arduamente para negociar con Hitler y evitar la guerra. El 1 de septiembre de 1939, Alemania invade Polonia y da inicio la guerra más vergonzosa y mortal que la humanidad haya experimentado: "La guerra había estallado ya en Europa. Una guerra que se iba a extender como mancha de aceite en todo el mundo. Abracadabramente espectáculo. Los ejércitos alemanes engullían estados como podían engullir pasteles" (Gil de Muro, 1998, p. 225).

Así las cosas, el expansionismo nazi ocupa Dinamarca, Noruega y Países Bajos. Francia se rinde seis semanas más tarde. Gran Bretaña decidió luchar contra un aliado nazi, Italia, primero en el norte de África y luego en la península Itálica. Hitler, una vez rendida Francia, dirige las fuerzas militares al este. Llega las fronteras de Moscú, pero el duro invierno frena sus proyectos de invasión. 
En 1941, EE.UU. entra a la guerra, tras el ataque de los japoneses en la base aeronaval de Pearl Harbor. Gran Bretaña gana los conflictos en Italia y Alemania, junto a los aliados ingresa a Italia y en 1943 comienzan la liberación. En Rusia, las batallas de Stalingrado y Kursk dejan como vencedor al ejército rojo. En 1944 Italia estaba prácticamente desalmada. El día "D" (6/6/1944) los aliados desembarcaron en Normandía (Francia) y avanzan hacia el Rin. Por el otro frente, el Ejército Rojo avanza hacia Berlín. En abril de 1945 los rusos ingresan a la ciudad, Hitler se suicida y el 7 de mayo Alemania se rinde. Nuevamente Alemania la gran perdedora.

Los resultados negativos de la II Guerra Mundial son asombrosos: 60 millones de muertos, millones de desplazados, refugiados y desaparecidos. Ciudades destrozadas y miles de prisioneros; en fin, un continente moral, material y humanamente destruido.

Se calcula que al menos fueron seis millones de judíos lo que murieron en los campos de concentración, gaseados y torturados injustamente. Otros judíos lograron emigrar al continente americano y así evitar la suerte del pueblo judío. Muchos familiares de Edith migraron a Suramérica para no morir en Alemania. La misma Edith tuvo la posibilidad de huir pero se mantuvo firme y esperó su destino como judía acompañando a su pueblo. A los tres años de la estancia de Edith en Echt "llegó la orden de las fuerzas de Ocupación que declaraba a todos los 
alemanes no arios en los Países Bajos apátridas, exigiéndoles inscribirse para la emigración hasta el 15 de diciembre" (Cfr. García, 1998, p. 177).

La valiente participación de Edith Stein en las dos guerras mundiales marcaría para siempre su camino. Durante la I Guerra Mundial, deja momentáneamente sus estudios en la Universidad de Gotinga para asistir a los enfermos y caídos del campo de batalla en un hospital austriaco. En una de sus notas escribiría “Ahora mi vida no me pertenece, me dije a mí misma: Todas mi energías están al servicio del Gran acontecimiento. Cuando termine la guerra, sí es que vivo todavía, podré pensar de nuevo en mis asuntos personales" (García, 1998, p. 80).

La II Guerra Mundial fue todavía peor para Edith, con una vida totalmente renovada es víctima de una de las ideologías más nefastas y humillantes que la humanidad haya conocido. Un genocidio de todo un pueblo. Sin justificación, sin racionamiento, sin ninguna explicación, el antisemitismo se filtró paulatinamente entre el nacionalismo alemán y empezó la persecución, la deportación y la emigración de los judíos. El 10 de abril de 1938 fue prácticamente el sello de la derrota para Edith. Era un día de elecciones en Alemania. Edith sabía de la suerte de los judíos, en las elecciones solo los arios podrían votar. Edith, siendo monja conventual, suplicó a sus hermanas que no votaran a favor de Hitler. La priora, sabiendo que Edith no era aria hizo todo lo posible para que ella votara y así salvarla de la persecución, empero fue imposible. Edith no salió a votar. Ya en noviembre de ese mismo año los judíos 
fueron víctimas de todo tipo de ultrajes por parte de las autoridades y del pueblo enajenado.

La vida intelectual de Edith Stein surge en la encrucijada de corrientes filosóficas que trataban de explicar el drama histórico entre guerras. La verdad del hombre y su misión en la tierra, fueron los ejes que impulsaron sus investigaciones y meditaciones. Su vida y pensamiento reflejan los momentos y situaciones que han caracterizado el naciente siglo XX. A continuación, se enumeran algunos de esos momentos.

Edith a los 14 años abandona la piedad judía. Hasta cierto punto se declara atea. El ateísmo es una de las características intelectuales del siglo XX. Es consecuencia de, al menos, dos tendencias claras: por un lado, las secuelas de un Renacimiento ilustrado que ha programado a un hombre moderno sin el auxilio de Dios y, por otro lado, el nihilismo que ha roto definitivamente la unión de la experiencia religiosa y deja al hombre solitario en el mundo. El racionalismo presente en las universidades alemanas ha terminado de moldear una filosofía atea-práctica que sirvió de plataforma filosófica a muchos intelectuales del siglo pasado. Edith absorbe esta tradición atea. Desde sus inicios como intelectual, entabló su filosofía en diálogo con las filosofías francesas y alemanas. El ateísmo, como fruto de la absolutización de la razón, fue fuertemente criticada por los fenomenólogos. Ellos no criticaban el racionalismo, sino la pretensión absolutista de este con respecto a la verdad. Al principio Edith quería estudiar psicología. Para ese entonces los cursos los 
dictaba Wilhelm Stern en Breslau (Sancho, 1998, p. 668; Lembeck, 1998, p. 969). Pero no conforme con los simples resultados naturalistas y mecánicos que ofrecía la psicología, decide adentrarse en la filosofía.

El primer encuentro de Stein con la filosofía se lo debe a Edmmund Husserl, Filósofo alemán y padre de la Fenomenología (1859-1938). Este autor trazó un proyecto para crear un método científico para la filosofía, alejada de todo prejuicio y subjetivismo. Este esfuerzo se materializó con el desarrollo de la teoría del método fenomenológico. De este autor, Stein leyó sus Investigaciones lógicas.

La fenomenología, entonces, era una experiencia nueva de conocer las cosas. Es la ciencia de la conciencia. Cada conciencia es conciencia de algo. Edith desarrolla, sobre las bases fenomenológicas, el concepto de Einfühlung (empatía): "se manifiesta como una forma de experiencia intersubjetiva que posibilita la constitución de un mundo objetivo" (Sancho, 1998, p. 674). Husserl propone la vuelta al sujeto trascendental como centro lógico y temático de su filosofía. Para él, el dogmatismo racionalista y el escepticismo empirista son consecuencia de un psicologismo gnoseológico del sujeto cognoscente. Solo trascendiendo al sujeto cognoscente se supera este psicologismo y se abre paso al sujeto trascendental (Cfr. Rábade, 1996, p. 8). 
El método fenomenológico se sitúa entre el idealismo de Hegel y el materialismo de Marx. Para el primero la verdad está en las ideas, en el sujeto; no en las cosas o los objetos. Para el segundo, la verdad está en las cosas, consideradas en su simple materialidad. Para el método fenomenológico, en cambio, la verdad es un acercamiento a los hechos, tal como los percibe la conciencia subjetiva; no son hechos puramente materiales ni puramente idealistas, sino hechos de conciencia subjetiva. El conocimiento fenomenológico trata de captar el fenómeno en la propia conciencia. No es subjetivismo puro, ni simple materialismo, sino percepción de los hechos de conciencia, tal como el sujeto los ve. Por tanto, ni teoría materialista ni idealista, sino simplemente realista; entendiendo "realista" o por "verdadero" el fenómeno percibido por la conciencia subjetiva (García, 1998, p. 101).

Stein sintetiza la desazón de la filosofía moderna que se ha visto en la problemática relativista y simplista de las verdades fundamentales. Ante la barbarie de las guerras, los etnocidios, los desplazamientos, etc., el sentido de la vida y la dignidad de la persona se vieron gravemente amenazados. El sentimiento de "vacío" que afrontaba el hombre (crisis antropológica) hizo que muchos intelectuales y filósofos ateos y no cristianos se convirtieran al cristianismo. 
En Alemania, la filosofía estaba impregnada del kantismo, tanto en su sentido clásico como en los movimientos neokantianos como el de Marburgo. La Universidad de Breslau, donde Stein empieza a estudiar psicología y germanística, también fue el alma mater de Hermmann Choen, padre de la Escuela de Marburgo. Dentro de esta propuesta Edith se ubica de lado del realismo ontológico (Lembeck, 1998, p. 691), abandona el idealismo kantiano. En este sentido, Edith abraza el realismo ontológico que proponía la escuela fenomenológica y a su estudio se dedicará los próximos años. «No olvidemos que Edith describía la fenomenología como una reacción frente al "idealismo crítico kantiano y al idealismo de cuño neokantiano"» (Cfr. García, 1998, p. 110).

Edith nunca abandonó los datos que le proporcionó la escuela fenomenológica. Hay que dejar claro que si bien Stein siempre reconoció los datos y el aporte de la escuela fenomenológica, abandona al Husserl viejo, o segundo Husserl, por su giro al idealismo. Para ella, una filosofía cabal tiene que ser realista.

Entre los años 1918 a 1921, Edith "decide abandonar a su maestro Husserl porque según ella, él había vuelto al idealismo trascendental" (Sancho, 1998, p. 674) y es en este período donde Edith elabora sus propias investigaciones. Encuentra en la fenomenología de Husserl un egocentrismo cognoscitivo, además, critica esta despiadada centralidad en el sujeto cognoscente, 
eliminando de facto toda posibilidad sobrenatural. Bajo esta perspectiva llegó a la Escolástica.

La filosofía de Edith, entonces, es una combinación de la escuela fenomenológica y el pensamiento tomista. Del primero tomó los aspectos realistas del mundo y del segundo recibió los aspectos de las cuestiones espirituales. Solo en el marco de un realismo filosófico se encuentra el diálogo con Aristóteles y Santo Tomás de Aquino. La síntesis de esta combinación se da entre razón y fe, tiempo y eternidad; existencia y esencia. A Edith le interesa un Santo Tomás que coincide con Husserl, en la confianza radical que ambos tienen en la capacidad intelectual del hombre. La diferencia estriba en que para su maestro la verdad absoluta era asequible por la sola razón, mientras que para el Aquinate esta verdad se daba por esfuerzo racional y gratuidad Divina.

Edith estuvo en contacto con los grandes pensadores del naciente siglo XX. Dentro del círculo de Gotinga conoció Max Scheler, ella misma reconoció que durante sus clases (a las que ella asistía) le despertó la conciencia religiosa. Este fenomenólogo de Gotinga figuró entre los principales exponentes de la fenomenología, en sus primeros inicios. Sus escritos reflejan una clara simpatía por los temas de la estética, la moral y el método filosófico. Estas ideas penetraron la inteligencia de Edith, de ahí que se declara deudora de su pensamiento junto a su Herr Professor. 
Edith no era desconocida ni desconocía el círculo filosófico alemán en el que se movía. Sus escritos, cartas y conferencias, muestran la altura y actualidad que mantenía, algo poco común para una mujer de su época. Mantiene encuentros epistolares con el filósofo polaco Roman Ingarden, el fenomenólogo de Polonia. Quizás uno de los pensadores que mejor conocía la vida y obra de Edith. Este autor "presentó la rehabilitación de la filósofa Edith Stein en 1968, en el palacio Episcopal de Cracovia, ante un público selecto. Este pensador había sido invitado por alguien que había sido profesor de ética y era entonces Obispo de Cracovia, Karol Wojtyla" (Feldmann, 1999, p. 111).

Debatió personalmente y entabló correspondencia filosófica con el fenomenólogo Adolfo Reinach. Después de Husserl, él representó para Edith el gran maestro; no sólo por sus valiosas aportaciones en el campo de la filosofía, sino por sus claras ideas religiosas. Estuvo en contacto con las ideas del converso francés Jacques Maritain a quien conoce durante un encuentro de estudiosos tomistas en París. Fue tal su cercanía con él que durante los inicios de la persecución nazi le escribe, el 21 de junio de 1933, una epístola donde se solidariza con su situación (García, 1998, p. 135).

En su tesis doctoral sobre la empatía, aborda el problema retomando el mismo concepto empático estudiado desde otros ángulos, como la estética y la psicología, por lo que consulta a varios autores como Teodoro Lipps, con quien se entrevistó, Moritz Geiger y Volkelt. El mismo Husserl entabla un diálogo 
con este filósofo muniqués y a su vez le comenta sobre el "gran trabajo de la señorita Stein" (García, 1998, p. 87).

Finalmente, Edith conversó muchas veces con Heidegger en Friburgo, intercambió ideas con este insigne pensador, mientras era auxiliar de Husserl. Con él debatió las ideas sobre ser-en-el-mundo. Para Edith el "ser" es anterior al espíritu que se sitúa ante él. No admitía la doctrina husserliana de una trascendencia sin Dios. Tampoco estaba de acuerdo con Heidegger que ponía todo el peso de la existencia en sí misma. Edith no creía que el ser humano era un "ser arrojado" (Feldmann, 1999, p. 109) al mundo de la nada y de la indiferencia. El ser no está solo en la existencia, sino que el Eterno irrumpe constantemente nuestra historia. Para Edith en el "Encuentro personal" el hombre encuentra el sentido de la vida, que no termina con la muerte sino todo lo contrario.

El sentido del ser en Edith es contrario al pensamiento heideggeriano. Edith razona, debate, aclara y redefine su pensamiento estableciendo una dialéctica con sus colegas; una apertura filosóficamente noble e intelectualmente humilde que le permitió profundizar y sintetizar un conocimiento valioso. 
El estudio de Edith Stein sobre la persona, se enmarca en las disciplinas de la fenomenológica y la metafísica. El ser humano es una persona singular e irrepetible. Para Edith el Hombre es bueno por naturaleza teleológica. La Revelación es el dato fundamental de la Teología, pero en el pensamiento steniano, lo es también para la antropología. Ella parte de la concepción tripartita del ser humano: cuerpo, alma y espíritu. El hombre es bueno por voluntad divina y está llamado, necesariamente, a lo bueno, esta es la única diferencia con respecto a los animales. Estas consideraciones antropológicas le servirán para plantear su pedagogía: la bondad de la naturaleza humana, la libertad del hombre, la llamada a la perfección y la responsabilidad del género humano. Pues para Edith hablar de pedagogía es hablar necesariamente de antropología.

Stein considera insuficiente una antropología natural —que bajo la influencia del evolucionismo biologicista estudia el hombre como especie — para servir de fundamento del saber pedagógico (Vilanou, 2002, p. 494). Según Edith, la antropología necesita de la metafísica cristiana. Una metafísica fundada en la antropología filosófica y teológica (Cfr. Delgado, 2007, p. 480).

Para Edith la interioridad no solamente es lugar, sino un camino de desenvolverse y desarrollarse. Quién descubre su interioridad, la acepta y la reafirma, toma decisiones libres, y solo el hombre que vive interiormente es libre. Dentro del pensamiento neokantiano alemán existen dos conceptos claves

\section{El concepto de persona humana}


para comprender la antropología steniana: Freiheit (Libertad) y el Geist (Espíritu). Ambos constituyen los pilares que funden la pedagogía empática de Stein. Para ella, Geist significa sencillamente «apertura». El espíritu es la dimensión de apertura de la persona, es lo que hace que la persona sea persona, radica en su dimensión dialógica. (Caballero, 2010, p. 42). Una apertura que llama a la libertad.

A partir de un aspecto de la antropología steniana: el concepto de persona. Se podría ubicar a esta pensadora dentro de la filosofía personalista de corte alemán, ya que cree que el ser humano está abierto a lo divino, a lo trascendente. El personalismo alemán se enmarca dentro de la fenomenología que se ubicaba en medio del positivismo lógico fuertemente antihumanista y los herederos del idealismo hegeliano antimaterialista (Cfr. Manuel, 2000, p. 119).

El ideario pedagógico de Edith Stein se fundamenta en un personalismo de raíz tomista que no se cierra, empero, a las aportaciones de la fenomenología al presentar la filosofía como apertura hacia nuevos horizontes de sentido, siendo uno de sus méritos haber vivificado la tradición de la filosofía perenne con la aportación de la fenomenología (Vilanou, 2002, p. 492). La persona es, por consiguiente, responsable porque es libre. "La libertad, qué duda cabe, media entre el yo, los motivos, la intencionalidad y las acciones por las que la persona opta. En este sentido, puede afirmarse que ni siquiera los motivos -al menos la mayoría de ellos que no son puramente tendenciales- escapan a esa libre 
conducción por la persona de su propia vida" (Polaino-Lorente, 2009, p. 58). Por eso mismo también ha de responder ante sí misma de lo que de sí misma ha hecho. Según esto el "hacerse" de la persona es un proceso de configuración progresiva; un configurarse desde dentro que constituye un peculiar modo de ser. "Lo que configura desde dentro es el principio de vida a que Aristóteles denominó con el término de alma o entelequia y Tomás de Aquino designó como forma interna" (Polaino-Lorente, 2009, p. 61).

Fue en la Universidad de Breslau donde Edith tuvo su primer encuentro con la pedagogía, su profesor William Stern se encargó de introducirla al mundo de la enseñanza y la psicología. Se doctoró en Filosofía (fue la primera mujer en doctorarse en esta disciplina en Alemania) y buscó, desafortunadamente, una cátedra universitaria. Concursó en las universidades de Breslau, Kiel, Friburgo y Gotinga. Sin embargo, las trabas burocráticas por su condición de mujer impidieron su ejercicio docente.

Entre 1923 a 1931 ejerció como docente en un Instituto dominico, en el 32 y 33 dirige la pedagogía en el recién creado Instituto Pedagógico de Münster. Dicta cursos tratando de vincular antropología y pedagogía, entre la idea del hombre y su formación. La pedagogía como vocación y misterio. La pedagogía steniana se enmarca no solo dentro de la fenomenología, sino también de la mística y del tomismo. Para Edith la educación "no consiste en la acumulación de conocimientos, sino en la adecuada configuración de la estructura interior,

\section{La antropología de la pedagogía empática}


esto es, una personalidad madura y plenamente desarrollada que tenga la posibilidad de abrirse al espíritu" (Vilanou, 2002, p. 487).

Se trata de un asunto muy complejo, nada fácil de explicar. La pedagogía debe preguntarse primero ¿qué es el hombre? Y así dirigir su esfuerzo en busca de su sentido y plenitud. Toda la labor educativa que se centra en educar a los hombres viene acompañada de una idea precisa de ¿qué es el hombre?, su lugar en el mundo y su misión en la vida, así como de las oportunidades prácticas ofrecidas para formarlo. Por esta razón desconfía de las conclusiones simplistas del: pedagogismo ilustrado, del positivismo pedagógico, del humanismo idealista, del neohumanismo pedagógico, del racionalismo, del psicoanálisis y del existencialismo heideggeriano. Ella defenderá una pedagogía "basada en una antropología de alcance metafísico que permita una consideración teológica -y no solo filosófica- de la vida humana" (Vilanou, 2002, p. 487).

La educación necesita del método teológico para encontrar su fin. Para Edith la tarea de educar está en orientar al estudiante a pensar bien, con verdad y claridad. "Educar es acompañar el despliegue completo de una humanidad en el cumplimiento de su vocación natural y sobrenatural. Esta es la única forma en que la sed de sentido que caracteriza a la persona humana, puede satisfacerse. Como un proceso de "autoperfeccionamiento" concepto utilizado con fuerza por el neoclasicismo alemán" (Cfr. Delgado, 2007, p. 482). Fue 
obligada a abandonar la docencia por las nuevas leyes antisemitas del nazismo que impedían a los judíos ser empleados públicos. En 1937, se encrudecieron las políticas y el Instituto fue clausurado definitivamente.

Pensamiento y obra en Stein son la misma cosa. El concepto de empatía que ella desarrolló lo experimentó también en su vida. Desde temprana edad, sintió una vocación hacia los demás que la impulsó a abandonar sus estudios universitarios para ayudar en enfermería durante la I Guerra Mundial. Como filósofa, la doctora Stein profundizó en la naciente escuela fenomenológica de su maestro Husserl. La fenomenología es método y camino; permite superar dualismos antropológicos "integra la experiencia y la reflexión, asume a la persona como un ser corporal, animado y espiritual, a través de sus vivencias intencionales, los valores, el poder y la libertad, con sus diversos significados y sentidos" (González Vega, p. 2005). No hay tiempo para detallar el método y naturaleza de la fenomenología. Sin embargo, precisa aquí centrar nuestra atención en su concepto de empatía.

Etimológicamente la empatía proviene del vocablo griego antiguo $\varepsilon \mu \pi \alpha \theta \varepsilon \iota \alpha$, formado $\varepsilon v$, 'en el interior de', y $\pi \dot{\alpha} \theta o \varsigma$, 'sufrimiento, lo que se sufre'. Significa, literalmente, ponerse en el lugar del otro, sentir en uno mismo al otro. No hay que confundir la empatía con el monismo o el panteísmo. El sentir 'algo' es un acto oferente y el sentir al sí mismo toca la constitución íntima de su yo. Cuando el sujeto toma conciencia del Otro y los otros "descubre" que nada le 
es ajeno ni indiferente y "siente" desde adentro y como propio el destino, el sufrimiento, la alegría y esperanza de todos. Por lo tanto, el Einfühlung no es una función del yo individual psicofísico, ni tampoco es un acto del Yo puro constituyente de los objetos conforme a las leyes de la conciencia en general, sino que es un acto espiritual de la persona, que le da a conocer simultáneamente el movimiento corporal orgánico del otro, sus capacidades psíquicas y la singularidad del yo personal ajeno como siendo una única realidad (Ferrer, 2007, p. 34).

Por la "apertura" "nos abrimos" sea también espíritu subjetivo, sea espíritu objetivo, sea el espíritu divino, o bien sea mi propia interioridad. Todos estos modos de apertura descansan sobre la empatía (Cfr. Caballero, 2010, p. 45). Para Stein no se ama a una persona porque hace el bien, sino porque ella misma es valiosa y por sí misma se ama, como vivencia intersubjetiva. Para llegar a ser quien se es, se precisa del encuentro y la relación con el otro. Una apertura al espíritu subjetivo. La empatía no es percibida, solo empatizada. Es un acto y no un recuerdo.

El itinerario steniano surca tres etapas: la fenomenológica, la tomista y la mística, sin que los límites o divisiones en estas áreas estén del todo claras. Gracias a este recorrido, la santa alemana, pudo convergir en una pedagogía empática. Rehabilita un realismo que retoma la confianza en el ser y en el fin teleológico, idea que incide claramente en su pedagogía. "La empatía le 
demuestra [...] que el hombre es un ser espiritual, trascendente, abierto, llamado a realizarse en lo más profundo de sí, pero sin dejar de confrontarse con el otro. Es un paso decisivo en ese camino ascendente hacia la comprensión del problema hombre y hacia la disposición a encontrarse con el otro" (Sancho, 2002).

Para Stein el ethos profesional solo es posible cuando la profesión se ejerce vocacionalmente. Para ella, la pedagogía es una reflexión profunda entre el objeto y el sujeto, encuentra su razón en una interacción, en un encuentro. Los alemanes lo llamaban el Bildung, que encuentra su razón de ser en el prójimo.

Para Edith la educación se resuelve de una manera empática, Einfühlung, como lo diría ella misma, y que se manifiesta como una forma de experiencia intersubjetiva que posibilita la constitución de un mundo objetivo. "La doctrina de la empatía nos decía precisamente que soy capaz de captarme a mí mismo como un yo cuando he empatizado con un tú" (Caballero, 2010, p. 54).

Stein no regatea ningún esfuerzo en la defensa del valor del ser humano, su cohumanidad, siempre abierta también hacia y para los demás, así como se muestra crítica respecto de la "desolidarizada orientación al rendimiento" propia de su tiempo. Cuestión esta que, de modo relevante, constituye una de las principales características de nuestro tiempo (Cfr. Polaino-Lorente, 2009, p. 48). Finalmente, Santa Teresa Benedicta de la Cruz nos invita a superar el 
solipsismo trascendentalista husserliano y el desesperante egocentrismo heideggeriano para depositar nuestra confianza e intelecto en una experiencia mística, cristificante y transformadora; en auténtica mistagogía para muchos que aún creen y luchan por un mundo cada vez más solidario y humano.

Edith y su búsqueda de la verdad simbolizan al hombre occidental moderno que apuesta a la filosofía para encontrar respuestas verdaderas de la realidad.

Conclusiones: Filosofía y vida Además, sintetiza la desazón de la filosofía actual que se ha visto en la problemática relativista y simplista de las verdades fundamentales. La dictadura del relativismo lleva al despeñadero existencial del hombre. Su conversión es un claro reflejo de la crisis que afronta la ciencia y filosofía de nuestro tiempo. Ante la barbarie de los etnocidios, los desplazamientos, el terrorismo, etc., el sentido de la vida y la dignidad de la persona se ven gravemente amenazadas. Solo un testimonio coherente y transfigurado puede dar respuestas a la crisis antropológica que sufre el hombre posmoderno, cada vez más angustiado y desesperado, vísperas de un mundo cada vez más inhumano, materialista y bizarro.

Vivimos, entonces, en una época caracterizada por una profunda ruptura entre la fe y cultura, así como una suerte de "fragmentariedad del saber", de tal forma que uno de los grandes retos que tenemos de cara al próximo milenio, es realizar el paso del fenómeno al fundamento y de llegar a una visión unitaria y orgánica del ser y del saber. Justamente por eso, la obra de Stein y, sobre todo, 
su vida, serán un punto de referencia muy importante, en orden a abordar con valentía este problema e ir encontrando una sana y equilibrada armonía entre la fe y la razón; la cultura y la religión. La actitud fundamental del discípulo no es la indagación, sino la escucha. Stein enseña al hombre posmoderno que debe renunciar a ser la medida de la verdad y hacerse siervo de la verdad y la caridad.

Respecto de verdad histórica, podemos decir que los acontecimientos que vivió Europa en la primera mitad del siglo XX y las corrientes filosóficas que marcaron el pensamiento alemán durante este período, marcaron profundamente el quehacer filosófico de Edith Stein. Mujer de origen judío, atea, filósofa, pedagoga, conferencista, conversa al catolicismo, carmelita descalza y asesinada en Auschwitz. Una vida, una pasión: la verdad. Mujer del siglo $\mathrm{XX}$, que sufrió la tragedia de las guerras, pero que supo salir airosa, de un pensamiento crítico y fino que le permitió dialogar con los pensadores más destacados de su época. Nos enseña que la verdad es una meta y no una bandera, que la caridad es auténtica cuando nos olvidamos de nosotros mismos y que el conocimiento es verdadero en cuanto más nos humaniza. Ofrece una propuesta de vida coherente en un mundo marcado por la indiferencia y el sinsentido, un mundo posmoderno e individualista que camina incierto e inseguro de sí mismo, y que lo peor de todo, no sabe ni siquiera a donde debería ir. 
Caballero, J. (2010). Ejes transversales del pensamiento de Edith Stein. En Revista Teología y vida, Vol. LI: 39-58.

Referencias bibliográficas

Delgado, I. (2007). Edith Stein: una visión filosófica y católica de la educación. En Revista Religión y Cultura, Vol. LIII: 463-498.

Feldmann, C. (1999). Edith Stein. Judía, filósofa y Carmelita. Barcelona: Herder (Original en Alemán, 1987).

Ferrer, U. (2007). Noción de persona en Edith Stein. En Revista Iberoamericana de Personalismo Comunitario, pág. 34-43.

García, C. (1998). Edith Stein o la búsqueda de la verdad. Reimpresión Burgos: Monte Carmelo.

Gil de Muro. (1998). Ahora que son las 12. Así era Edith Stein. Burgos: Monte Carmelo.

González, F. (2005). La decisión humana en Edith Stein y los aportes de la fenomenología a la mística. Lección inaugural CITeS-Ávila.

Lembeck, K. (1998). De la Crítica a la mística. Edith Stein y el neokantianismo de Marburgo. En Revista Anuario Filosófico, Vol. 31: 689-708.

Manuel, J. (2000). El personalismo. Madrid: Palabra. 
Polaino-Lorente, A. (2009). La estructura de la persona según Edith Stein. En Revista Metafísica y persona. Año 1, nº 2: 45-71.

Rábabe, S. (1966). El sujeto trascendental en Husserl. En Anales del Seminario de Metafísica: 7-27.

Sancho, F. (1998). Filosofía y vida: El itinerario filosófico de Edith Stein. En Anuario Filosófico, Vol. 31 (3): 665-687.

. (Ed.). (2002). Edith Stein. Obras selectas. Burgos: Monte Carmelo.

Stein, E. (1992). Estrellas amarillas (Traducción de Carlos Castro). Madrid: Espiritualidad (Original en alemán 1939). (2004). El problema de la empatía (Traducción de José Luis Caballero Bono). Madrid: Trotta (Original en alemán 1917).

Sullivan, J. (2003). Edith Stein. Escritos esenciales. (Trad. M ${ }^{\mathrm{a}}$ del Carmen Blanco Moreno). España: Sal Terrae (Original del inglés, 2002). 